\title{
EINE NEUE METHODE ZUR BEURTEILUNG DER FÄKALEN VERUNREINIGUNG EINES· WASSERS, GEGRÜNDET AUF DIE VERÄNDERLICHKEIT DES GASBILDUNGSVERMÖGENS VON B. COLI.
}

\section{AKADEMISCHE ABHANDLUNG ZUR}

ERLANGUNG DER DOKTORWURDE MIT GENEHMIGUNG

DER

MEDIZINISCHEN FAKULTÄT ZU LUND

ZUR ÖFFENTLICBEN BEURTEILUNG VORGELEGT

VON

BERNT HENNINGSSON, MED. LIC.

LEIPZIG,

VEIT \& C O M P. 
Sonderabdruck aus der

"Zeitschrift für Hygiene und Infektionskrankheiten". Bd. LXXIV. 1913.

Druck von Metzger \& Wittig in Leipzig. 